\title{
Estimation of Grain Boundary Sliding During Ambient-Temperature Creep in Hexagonal Close-Packed Metals Using Atomic Force Microscope
}

\author{
Tetsuya Matsunaga and Eiichi Sato \\ Institute of Space and Astronautical Science, Japan Aerospace Exploration Agency \\ Japan
}

\section{Introduction}

Grain-boundary sliding is one of important deformation mechanisms during creep, which is generally activated by a diffusion process. The apparent activation energy $(Q)$ of the phenomenon is similar to that of dislocation-core diffusion (Frost \& Ashby, 1982), and affects creep at high temperatures. However, the present authors observed another type of grainboundary sliding activated by a remarkably low $Q$ value of about $20 \mathrm{~kJ} / \mathrm{mol}$ for ambienttemperature creep in hexagonal-close packed metals and alloys. The $Q$ value is about onefourth of that of grain boundary diffusion of each material (Matesunaga et al., 2009a).

Heretofore, grain boundary sliding has been measured using scribe lines or micro-grid on the specimen surface which was fabricated by a small needle (Harper et al., 1958), focused ion beam (Koike et al., 2003; Rust and Todd, 2011), or stencil method (Parker and Wilshire, 1977). However, atomic force microscope is much more convenient method to measure a vertical component of grain-boundary sliding than the other method because of no advance preparation. In this chapter, to reveal a detailed role of grain-boundary sliding on ambienttemperature creep, atomic force microscopy was conducted to measure a travel distance of it.

Ambient-temperature creep was observed about a half century ago in pure Ti (Adenstedt, 1949; Kiessel \& Sinnott, 1953; Luster et al., 1953). Since that time, several studies of this phenomenon have been carried out using Ti alloys. Several Ti alloys were investigated in the 1960s and 70s such as Ti-5Al-2.5Sn (Kiefer \& Schwartzberg, 1967; Thompson \& Odegard, 1973) and Ti-6Al-4V (Reiman, 1971; Odegard \& Thompson, 1974; Imam \& Gilmore, 1979). Later, Mills' group intensively studied this phenomenon using Ti-6Al and Ti-6Al-2Sn-4Zr-2Mo (Suri et al., 1999; Neeraj et al., 2000; Deka et al., 2006). Among these experimental studies restricted to Ti alloys, the present authors found recently that all hexagonal close-packed metals and alloys show creep behavior at ambient temperature below their $0.2 \%$ proof stresses, but no cubic metals or alloys show it under the same condition (Sato et al., 2006). The former group included commercially pure Ti, magnesium, zinc, Ti-6Al-4V, Zircaloy-4, and AZ31, and the latter group included pure iron, $5052 \mathrm{Al}$, and Ti-15V-3Cr-3Sn-3Al. In addition, the authors introduced a new region into the Ashby-type deformation mechanism map of commercially pure titanium, the ambient-temperature creep region (Tanaka et al., 2006). 
In the ambient-temperature creep region, the authors identified dominant intragranular deformation as a planar slip with no tangled dislocation, which lies on a single slip plane, by transmission electron microscopy (Matesunaga et al., 2009b). The reason why only one slip system is activated inside of a grain is low crystalline symmetry of hexagonal close-packed structure. Its creep parameters were, then, obtained that a stress exponent $(n)$ of 3.0 and a grain-size exponent $(p)$ of 1.0 despite the creep is a dislocation creep. According to these experimental results, we proposed a constitutive relation of ambient-temperature creep as

$$
\dot{\varepsilon}_{s}=A D_{0} \exp \left(-\frac{Q}{R T}\right) \frac{G b}{k T}\left(\frac{\sigma}{E}\right)^{n}\left(\frac{b}{d}\right)^{p},
$$

where $A$ is a dimensionless constant, $D_{0}$ is a frequency factor, $G$ is a shear modulus, $R$ is the gas constant, $k$ is Boltzmann's constant, $b$ is a Burgers vector, $\sigma$ is applied stress, $E$ is a Young's modulus, and $d$ is a grain size.

The positive $p$ value means that grain boundaries function as a barrier to dislocation motion and lattice dislocations pile up at grain boundaries. On the other hand, the high-temperature dislocation creep possesses zero $p$ value, which means dislocations can propagate to an adjacent grain easily. In addition, backflow is observed after complete stress-drop tests which mean that the recovery rate controls ambient-temperature creep (Matsunaga et al, $2009 \mathrm{~b})$. Results in the previous paper also claimed that grain boundary must accommodate piled-up dislocations to continue and to rate-control deformation because no obstacles exist against dislocation motion inside of a grain.

Describing above, the intragranular deformation mechanism have been studied and discussed well, whereas a role of grain boundary has not been revealed despite of the positive $p$ value of unity. To reveal detailed intergranular deformation mechanism, atomic force microscopy was effective to measure the travel distance of grain-boundary sliding. In addition, electron back-scattered diffraction pattern analysis was conducted to observe grain-boundary structure. Combining of these technics, actual influence of grain boundary on deformation was evaluated.

\section{Experimental procedure}

The sample was rolled sheets of pure zinc with $d$ of $210 \mu \mathrm{m}$ and its purity was 99.995 mass\%, which shows considerable creep at ambient temperature, as do other hexagonal closepacked materials. No impurity was detected using inductively coupled plasma optical emission spectroscopy (ICPS-8000, Shimadzu). Zinc has also been used for the study on grain-boundary deformation based on a displacement-sift-complete dislocation model above $0.7 T_{\mathrm{m}}$ (Bollmann, 1967; Schober et al., 1970). Therefore, the features between low- and high-temperature deformation modes at grain boundaries can be compared.

Tensile tests were performed to evaluate $0.2 \%$ proof stress $\left(\sigma_{0.2}\right)$ at ambient temperature with a constant crosshead speed corresponding to an initial strain rate of $1 \times 10^{-3} \mathrm{~s}^{-1}$ using an Instron-type machine (AG-100KGN, Shimadzu). Tensile creep tests were then conducted using a dead-load creep frame with loads below $\sigma_{0.2}$ up to $4.3 \times 10^{5} \mathrm{~s}$. Then, some tests were conducted with $0.8 \sigma_{0.2}(19 \mathrm{MPa})$ at $300 \mathrm{~K}$; they were interrupted after $0.18 \times 10^{5} \mathrm{~s}, 0.86 \times 10^{5} \mathrm{~s}$, $2.6 \times 10^{5} \mathrm{~s}$ and $4.3 \times 10^{5} \mathrm{~s}$, respectively. In the both tests, the loading direction corresponded to 
the rolling direction. Strain was measured using strain gauges with a resolution of $3 \times 10^{-6}$ mounted directly on the specimen surfaces. By reducing creep of the strain gauge itself, a strain rate of $1 \times 10^{-10} \mathrm{~s}^{-1}$ was measured directly. These creep curves were fitted by the logarithmic creep equation (Garofalo, 1963) to evaluate steady state creep rates:

$$
\varepsilon=\varepsilon_{i}+\varepsilon_{p} \ln \left(1+\beta_{p} \mathrm{t}\right)+\dot{\varepsilon}_{\mathrm{s}} \mathrm{t}
$$

where $\varepsilon$ is true strain, $\varepsilon_{\mathrm{i}}$ is instantaneous strain, $\varepsilon_{\mathrm{p}}$ and $\beta_{\mathrm{p}}$ are parameters characterizing primary creep region, and $t$ is the elapsed time. Temperature dependent of Young's modulus was calculated from the data of Ashby's textbook (Frost \& Ashby, 1982); Poisson's ratio of zinc equals 0.244 (Chen \& Sundman, 2001).

Optical microscopy (VHX-600, Keyence), electron back-scattered diffraction pattern analyses (OIM, TSL) were performed before and after the creep tests. The specimens were polished mechanically using colloidal silica before the microscopy. Electron back-scattered diffraction pattern analyses revealed no distortion in a grain before the tests and lattice-rotation distribution after those.

After mechanical tests, vertical components of grain-boundary sliding were measured at more than 40 grain boundaries using an atomic force microscope (VN-8000, Keyence) with a scan speed of $1.11 \mathrm{~Hz}$ on contact mode with scanning area of $100 \times 100 \mu \mathrm{m}$ for each observation. In this condition, an accuracy of an amount of grain-boundary sliding is $0.1 \mathrm{~nm}$. The flatness of surface at grain boundary before the tests was also confirmed by this technique.

The contributions of grain-boundary sliding to the total creep strain, $\varepsilon_{G B S}$, were calculated for individual grains using

$$
\begin{gathered}
\varepsilon_{\mathrm{GBS}}=\frac{u}{d} \\
=\frac{k v}{d}
\end{gathered}
$$

where $u$ is the travel distance parallel to the tensile direction and $v$ is that perpendicular to the sample as well as to the tensile direction, $k$ is a geometrical factor with the value of 1.1 (Bell \& Langdon, 1967). In this study, the authors evaluated $v$ by atomic force microscopy.

\section{Experimental result}

Figures $1 \mathrm{a}$ and $1 \mathrm{~b}$ are optical microscope images of specimen surfaces taken after creep tests of $0.18 \times 10^{5} \mathrm{~s}$ and $2.6 \times 10^{5} \mathrm{~s}$, respectively, with the load of $19 \mathrm{MPa}$ at $300 \mathrm{~K}$. Flat surface was confirmed before the tests, whereas Figs. $1 \mathrm{a}$ and $1 \mathrm{~b}$ show slip lines on the surface and grain boundaries become apparent with increasing the test time. In addition, they show that only one slip line was activated inside each grain. This description coincides with the results of previous transmission electron microscopy (Matsunaga et al., 2009 b). Figure 1c is an 3-D profile image with aspect ratio of 10:1 taken after a creep test of $4.3 \times 10^{5} \mathrm{~s}$ by atomic force microscopy. It is a joined picture of five observations. This image also shows slip lines and 

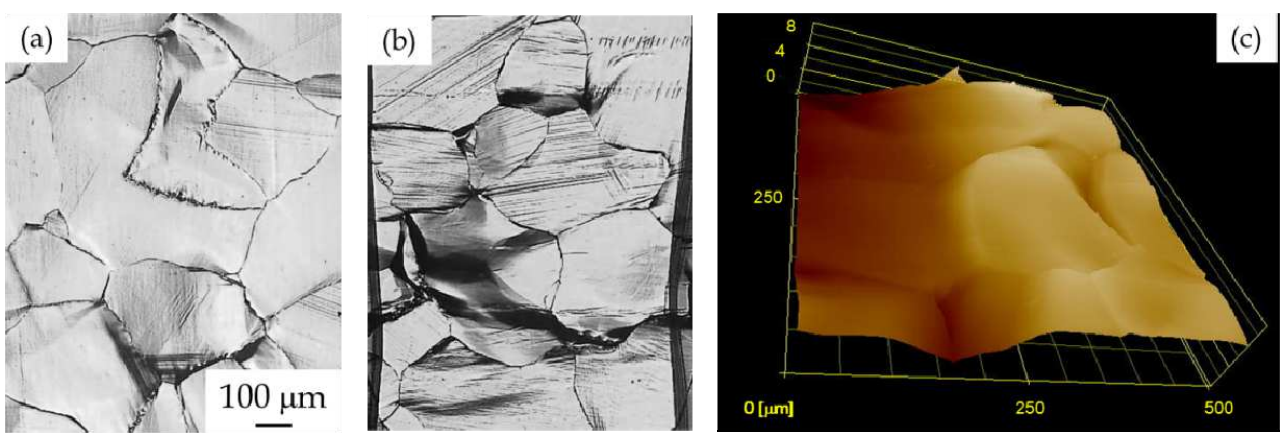

Fig. 1. Optical microscope images of specimen surfaces taken after creep test of (a) $1.8 \times 10^{5} \mathrm{~s}$, and (b) $2.6 \times 10^{5} \mathrm{~s}$. (c) 3 -D surface profile taken after creep test of $4.3 \times 10^{5} \mathrm{~s}$. Traces of grain boundaries and slip lines become significant with increasing the test time.

steps at grain boundaries clearly. An average height of the steps for the observed grain boundaries is about $1.0 \mu \mathrm{m}$.

Figure 2a shows a creep curve (solid line) and a time dependency of $\varepsilon_{\mathrm{GBS}}$ (closed circles) under the same condition with that in Fig. 1. A broken line is a fitting curve of $\varepsilon_{\mathrm{GBS}}$ using equation (2). Creep behavior was observed significantly for both creep strain $\left(\varepsilon_{\text {creep }}=\varepsilon-\varepsilon_{\mathrm{i}}\right)$ and $\varepsilon_{\mathrm{GBS}}$. The strain rate by grain-boundary sliding at the infinite period is evaluated as $2.1 \times 10^{-10} \mathrm{~s}^{-1}$, which is only $6 \%$ of the steady-state creep rate on the same condition. Moreover, $\varepsilon_{\mathrm{GBS}}$ yielded most of the creep strain immediately after loading, but $\varepsilon_{\mathrm{GBS}} / \varepsilon_{\text {creep }}$ decreased by $33 \%$ at $4.3 \times 10^{5} \mathrm{~s}$ as shown in Fig. $2 \mathrm{~b}$. It indicates that main part of the strain is yielded by the dislocation motion inside of grains in ambient-temperature creep region. (Matsunaga et al., 2010)



(a)

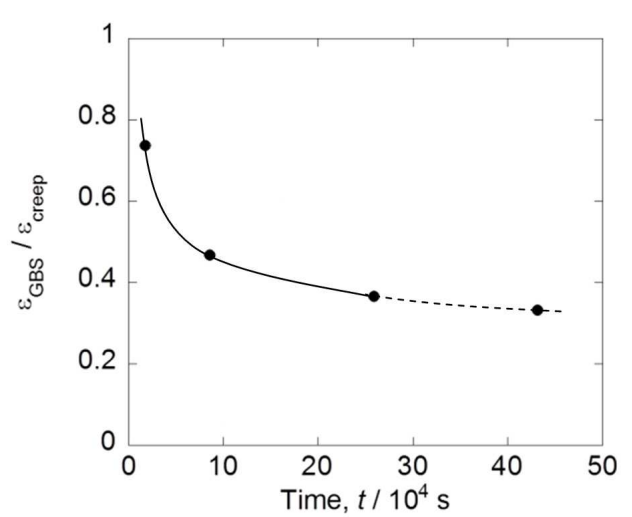

(b)

Fig. 2. (a) Creep strain and $\varepsilon_{\mathrm{GBS}}$ with $19 \mathrm{MPa}$ at $300 \mathrm{~K}$ (Matsunaga et al., 2010). (b) Time dependency of $\varepsilon_{\mathrm{GBS}} / \varepsilon_{\mathrm{creep}}$ under the same condition. $\varepsilon_{\mathrm{GBS}}$ increase with lasting time, but contribution of $\varepsilon_{\mathrm{GBS}}$ on $\varepsilon_{\text {creep }}$ decreases. 
Figure $3 \mathrm{a}$ is an optical microscope image taken after a creep test for $4.3 \times 10^{5} \mathrm{~s}$. Atomic force microscopy was conducted along a white line in Fig. 3a, and a surface profile shows a displacement of $0.77 \mu \mathrm{m}$ at the grain boundary as shown in Fig. 3b. Figures $3 \mathrm{c}$ and $3 \mathrm{~d}$ portrays results of electron back-scattered diffraction pattern analyses in a white flame in Fig. 3a before and after the creep test. They depict crystal orientation maps and the red point in Fig. $3 \mathrm{c}$ was the base point of orientation. Figure $3 \mathrm{c}$ was colored blue all around, which means that there were no change of crystal orientation near the grain boundary. On the other hand, Fig. $3 \mathrm{~d}$ showed gradations with widths of $20 \mu \mathrm{m}$ near the grain boundary, which implies that the change of crystal orientation of about five degree exists. Orientation gradient near grain boundaries is introduced by lattice dislocations which distort crystal lattice by piled-up dislocations. Figures $3 \mathrm{c}$ and $3 \mathrm{~d}$ demonstrate that recrystallisation did not occur because the shape of the grain boundary was maintained during the creep test (Matsunaga et al., 2010).
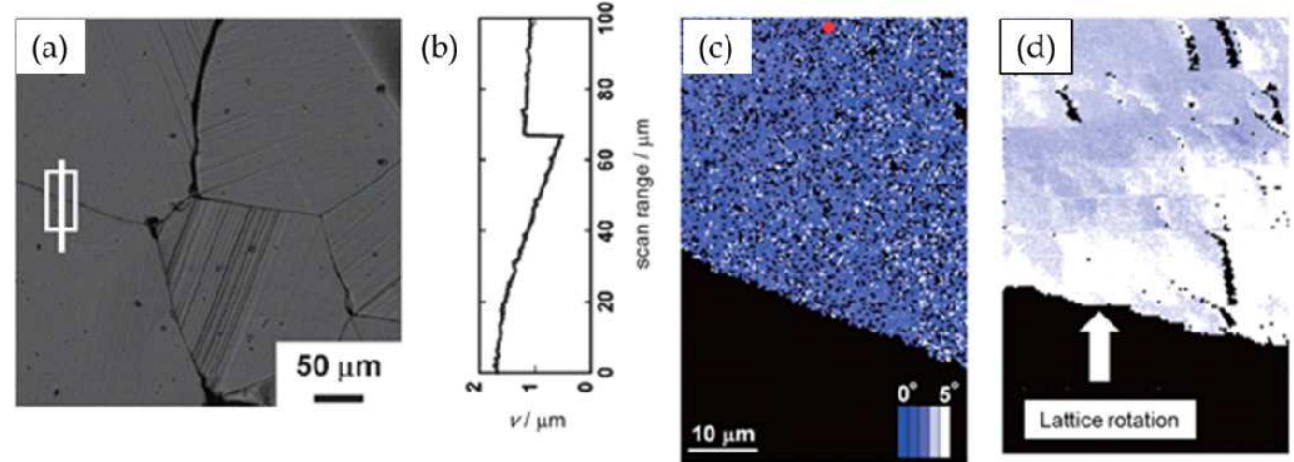

Fig. 3. (a) Optical microscope image taken after the creep test of $4.3 \times 10^{5} \mathrm{~s}$. (b) Surface profile at the white line in (a) showing $v=0.77 \mu \mathrm{m}$. Cristal orientation maps taken before (c) and after (d) the creep test with $19 \mathrm{MPa}$ (Matsunaga et al., 2010). They imply that the change of crystal orientation of about five degree after the test.

A grain-boundary-structure dependency of $\varepsilon_{G B S}$ in the ambient-temperature creep region was then analyzed in Fig. 4. The data of grain boundaries having a common axis of $<10 \overline{1} 0>$ were picked up. Grain boundaries with $\Sigma$ number slide slightly compared to random grain boundaries. It is similar to the results described by Watanabe et al. (Watanabe et al., 1979, 1984).

\section{Discussion}

Because hexagonal close-packed materials have low crystal symmetry, strain compatibility is not satisfied at grain boundaries. Although five independent slip systems are necessary for bringing about creep in polycrystals (the von Mises condition), basal or prismatic slip system in the structure has only two or three independent slip systems, respectively. This necessitates some accommodation mechanisms acting at grain boundaries. Because the observed $Q$ value $(20 \mathrm{~kJ} / \mathrm{mol})$ is much smaller than those of diffusion processes, they are not activated. A possible mechanism of grain-boundary sliding of ambient temperature is slip-induced grainboundary sliding (Valiev \& Kaibyshev, 1977; Mussot et al., 1985; Koike et al., 2003). 


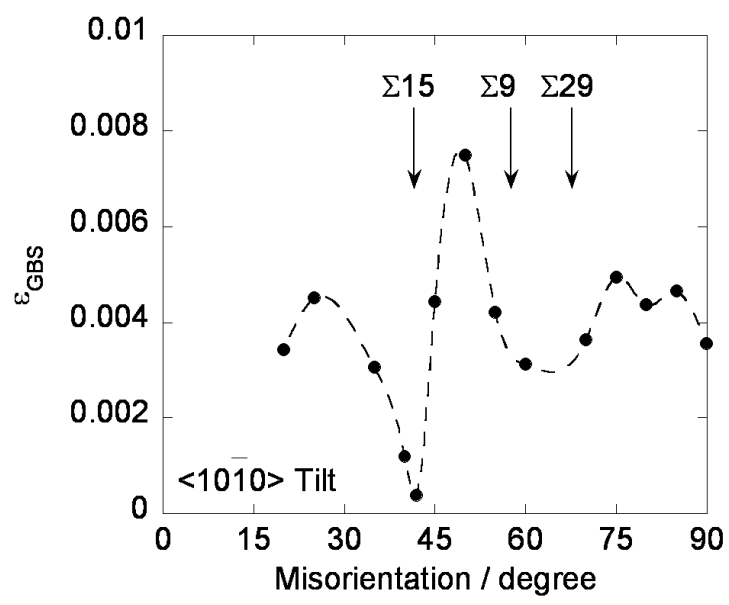

Fig. 4. Grain-boundary-structure dependency of $\varepsilon_{\mathrm{GBS}}$ of grain boundaries having a common axis of $<10 \overline{1} 0>$. $\Sigma$-numbered grain boundaries slide more slightly than random grain boundaries (Matsunaga et al., 2010).

Figure 5 describes a model of slip-induced grain-boundary sliding as follows; intragranular glide is activated first (Fig. 5a); plastic compatibility is responsible for internal stresses, which might be sufficiently strong to activate grain-boundary sliding. This activation is an incompatible process that is responsible for a new internal stress field, which modifies the plastic and total strain distribution near the sliding grain boundary by absorption of piledup dislocations (Fig. 5b), so that the final intragranular and intergranular total strain distributions are compatible with grain-boundary sliding (Fig. 5c). Magnesium alloy (AZ31) had shown the grain-boundary sliding during tensile deformation in near room temperature with an estimated $Q$ value of $15 \mathrm{~kJ} / \mathrm{mol}$ (Koike et al., 2003). Features of the slip-induced grain-boundary sliding satisfy the condition of ambient-temperature creep of hexagonal close-packed metals.

On the other hand, grain-boundary sliding at coherent grain boundaries was described by the displacement-sift-complete dislocation (Bollmann, 1964; Schober, 1970) using zinc and aluminum bicrystals at temperatures higher than $0.7 T_{\mathrm{m}}$ (Rae \& Smith, 1980; Smith \& King, 1981; Takahashi \& Horiuchi, 1985). In this model, grain boundaries slide through the movement of grain boundary dislocations absorbed at a grain boundary with a diffusion process. It is showed that the amount of grain-boundary sliding varied by grain boundary structure (Watanabe et al, 1979, 1984).

In this study, the grain-boundary-structure dependency of grain-boundary sliding in ambient-temperature creep in zinc was then analyzed (Fig. 5). $\Sigma$-numbered grain boundary only slides slightly compared to random grain boundaries similar to the behavior of hightemperature grain-boundary sliding (Watanabe et al., 1979, 1984). And, it is considered that grain boundaries having a stable structure (a $\Sigma$ number) hardly absorb piled-up dislocations. However, in this temperature region, it is believed that diffusion processes do not function, and that a different process of grain-boundary sliding is activated during the ambienttemperature creep. 


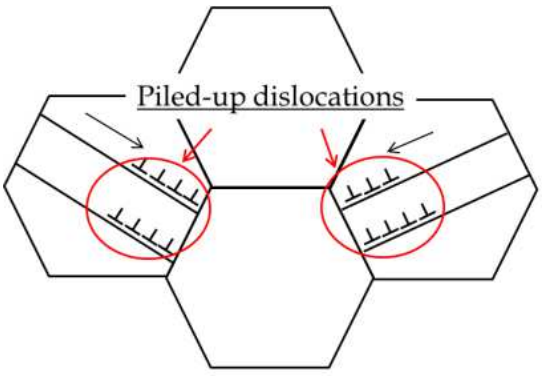

(a)



(b)

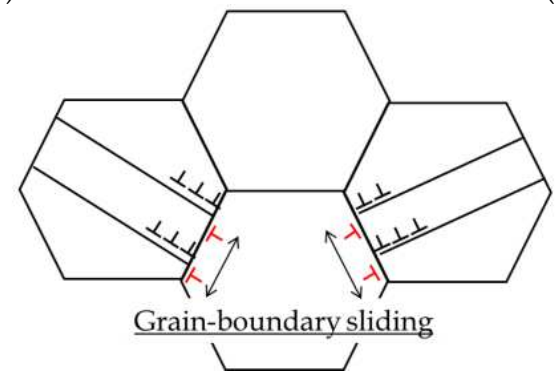

(c)

Fig. 5. Schematic drawing of slip-induced grain-boundary sliding: (a) pile-up lattice dislocations at grain boundaries, (b) which absorb these dislocations, (c) and thereby generating grain-boundary sliding.

Based on the discussion presented above, a constitutive relationship for the ambient temperature creep is considered. Because of a barrier against dislocation motion inside of each grain, the creep is controlled by recovery at grain boundaries. Therefore, a steady state creep rate is expressed as

$$
\dot{\gamma}=\frac{r}{h},
$$

where $r(=\mathrm{d} \tau / \mathrm{dt})$ is the recovery rate and $h(=\mathrm{d} \tau / \mathrm{d} \gamma)$ is the work-hardening rate (Orowan, 1934). In this condition, the stress applied to the leading dislocation piled up at the grain boundary, $\tau$, is expressed as $N G b / \pi L$ where $N$ denotes the number of piled-up dislocations $\left(=\rho L^{2}, \rho\right.$ is the dislocation density), and $L$ is the pile-up distance. The shear strain $\gamma$ is related with the dislocation density as $s b \rho$ where $s$ is the displacement of dislocations. Because $h$ can be explained as $(d \tau / d \rho)(d \rho / d \gamma)$,

$$
h=A \frac{G^{2} b}{s \tau} .
$$

Since the slip-induced grain-boundary sliding with shuffling proceeds through the dislocation absorption, the climbing rate based on the theory of superplasticity could be applied as a time-dependent change of dislocation density near the grain boundary, where is limited to $b^{2} d$. Thus, $\mathrm{d} \rho / \mathrm{d} t$ is expressed as following equation: 


$$
\frac{d \rho}{d t}=\frac{A D}{b^{2}}\left(\frac{G b}{k T}\right)\left(\frac{b}{d}\right)^{3}\left(\frac{\tau}{G}\right)^{2},
$$

where $D$ is the diffusivity. Therefore, since $r$ can be expressed as $(d \tau / d \rho)(d \rho / d t)$,

$$
r=A D\left(\frac{G^{2} b}{k T}\right)\left(\frac{b}{d}\right)^{2}\left(\frac{\tau}{G}\right)^{2} .
$$

Substituting equations (3) and (5) into equation (2) and interpreting $s$ as $d$ because there is few obstacles on dislocation motion inside of grains, the steady state creep rate is expressed by the equation (9);

$$
\dot{\varepsilon}=A D_{0}\left(\frac{G b}{k T}\right)\left(\frac{\sigma}{E}\right)^{3}\left(\frac{b}{d}\right) \exp \left(-\frac{Q}{R T}\right)
$$

The effective diffusivity $\left(D_{\text {eff }}\right)$ (Springarn et al., 1979) is given by the diffusivity of body diffusion $\left(D_{\mathrm{v}}\right)$, dislocation-core one $\left(D_{\mathrm{d}}\right)$ and shuffling $\left(D_{\mathrm{s}}\right)$ :

$$
D_{\text {eff }}=D_{\mathrm{p}}+\alpha\left(\frac{\tau}{G}\right)^{2} D_{\mathrm{d}}+\left(\frac{b}{d}\right) D_{\mathrm{s}},
$$

where $\alpha$ is a constant. Using the effective diffusion, all dislocation creep regions are expressed by an identical constitutive relation at all temperatures. Considering at very low temperature where the third term becomes dominant, equation (1) is obtained.

Using the constitutive relation, i.e., equation (9), the conventional deformation mechanism maps of hexagonal-close packed metals are rewritten. These maps of metals and alloys are often plotted in Ashby-type (Frost \& Ashby, 1982) or Langdon-type (Langdon \& Mohamed, 1978) maps. Each map is composed of modulus-compensated applied stress, homologous temperature and strain rate, and gives a particular deformation mechanism as a function of these parameters. Therefore, the maps are used to select a structural material in a design condition. In this paper, the Langdon-type map is used because each deformation region is split with a straight line.

The creep parameters of zinc are listed in Table 1 which includes the values of conventional creep regions represented by Ashby's textbook (Frost \& Ashby, 1982). Figures 6a and 6b are conventional and modified deformation mechanism maps of zinc with $d$ of $100 \mu \mathrm{m}$ using the parameters in Table 1. The ambient-temperature creep region appears at low temperatures in the modified map. By means of this experiment, the detailed deformation mechanism maps of hexagonal close-packed metals are proposed and the new creep mechanisms are revealed.

Ultra-fine grained metals might show the similar deformation mechanism at low temperatures because they do not have any spaces generating cell structure inside of grains, which means that dislocation-grain-boundary interaction, i.e., slip-induced grain boundary sliding, becomes significant comparing with coarse-grained metals, bringing about the creep. Therefore, the kind of metals shows creep similar to the ambient-temperature creep of hexagonal close-packed metals. To reveal the above assumption, mechanical tests and some microscopy are in action using ultra-fine grained aluminum. 


\begin{tabular}{|c|c|c|c|}
\hline & $n$ & $p$ & $Q[\mathrm{~kJ} / \mathrm{mol}]$ \\
\hline Ambient-temperature creep & 3.4 & 1.2 & 18 \\
\hline Low-temperature dislocation creep & 6.5 & 0 & 60 \\
\hline High-temperature dislocation creep & 4.5 & 0 & 92 \\
\hline Coble creep & 1.0 & 3.0 & 60 \\
\hline Nabarro-Herring (N-H) creep & 1.0 & 2.0 & 92 \\
\hline
\end{tabular}

Table 1. Creep parameters of zinc

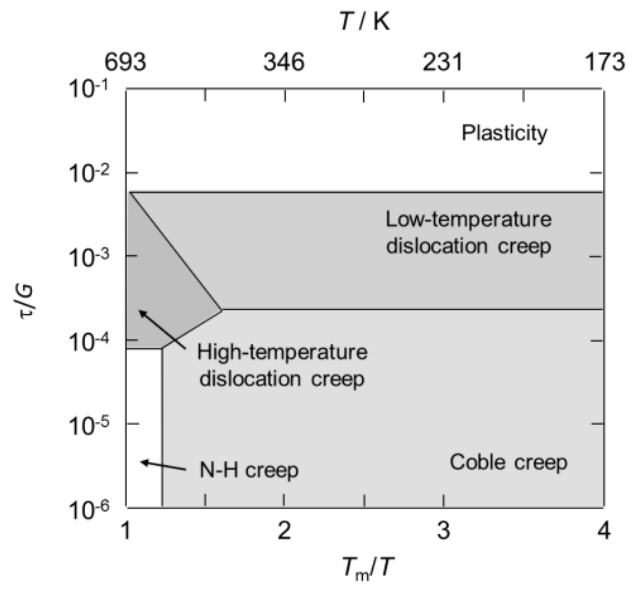

(a)

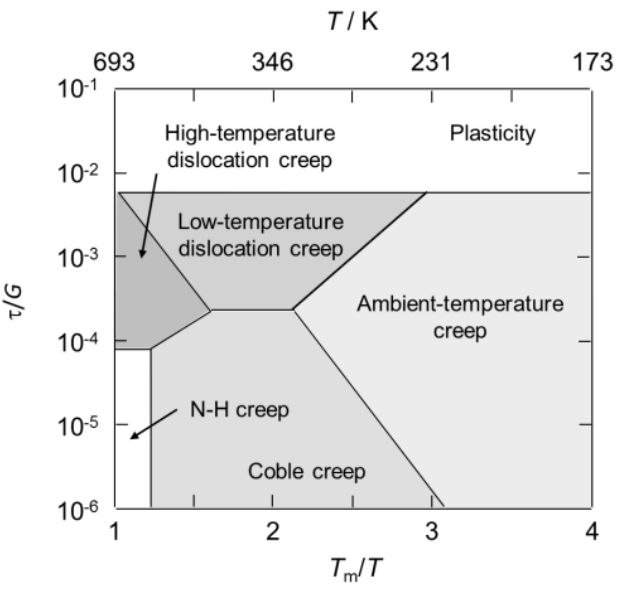

(b)

Fig. 6. (a) Conventional and (b) modified deformation mechanism maps of zinc. Using the parameters in Table1, the ambient-temperature creep region appears at low temperatures.

\section{Conclusions}

The role of the intergranular deformation mechanism was investigated to reveal an accommodation process in ambient-temperature creep of hexagonal close-packed metals using zinc by atomic force microscopy and electron back-scattered diffraction pattern analyses before and after the creep tests. Then, it evaluated the extension of grain-boundary sliding and revealed the role of grain boundary. These experiments produced the following important results:

1. Lattice rotation of about five degree is observed after a creep test, which shows that lattice dislocations piled up at grain boundaries.

2. Dislocations do not pass through grain boundaries because of the lack of equivalent slip systems in the hexagonal close-packed structure.

3. Grain boundary sliding depends on the grain boundary structure. The $\Sigma$-numbered grain boundary does not slide in ambient-temperature creep.

4. Strain by grain boundary sliding contributes to about $30 \%$ of the entire creep strain.

Therefore, the general representation of the ambient-temperature creep is described in Figs. 5 and 6 as a new creep mechanism. 


\section{Acknowledgment}

The authors sincerely appreciate Prof. Takeshi Ogawa, Aoyama Gakuin University, for atomic force microscopy. The authors also appreciate funding and support from a Grant-inAid for Scientific Research and a Fellowship (08J00141) from the Japan Society for the Promotion of Science.

\section{References}

Adenstedt H. (1949). Creep of titanium at room temperature, Metal Progress, Vol.56, (November 1949), pp.658-660.

Bell, R.L. \& Langdon T.G. (1967). An investigation of grain-boundary sliding during creep, Journal of Materials Science, Vol.2, No.4, (May 1967), pp.313-323, ISSN 0022-2461.

Blum, W. \& Zeng, X.H. (2009). A simple dislocation model of deformation resistance of ultrafine-grained materials explaining Hall-Petch strengthening and enhanced strain rate sensitivity, Acta Materialia, Vol.57, No.6, (April 2009), pp.1966-1974, ISSN 1359-6454.

Bollmann, W. (1967). On the geometry of grain and phase boundaries I. General theory, Philosophical magazine, Vol.16, No.140, (March 1967), pp.363-381, ISSN 0031-8086.

Chen, Q \& Sundman B. (2001). Calculation of debye temperature for crystalline structures a case study on Ti, Zr, and Hf, Acta Materialria, Vol.60, No.6, (April 2001), pp.947961, ISSN 1359-6454.

Deka, D.; Joseph, D.S.; Ghosh, S. \& Mills, M.J. (2006). Crystal plasticitymodeling of deformation and creep in polycrystalline Ti-6242, Metallurgical and Materials Transactions A, Vol.37, No.5, (May 2006), pp.1371-1388, ISSN 1073-5623.

Frost, H.J. \& Ashby, M.F. (1982). DEFORMATION-MECHANISM MAPS, Pergamon Press, ISBN 0-08-0293387, Oxford, England.

Furukawa, M.; Horita, Z.; Nemoto, M.; Valiev, R.Z. \& Langdon, T.G. (1996). Microhardness measurements and the Hall-Petch relationship in an Al-Mg alloy with submicrometer grain size, Acta Materialia, Vol.44, No.11, (November 1996), pp.46194629, ISSN 1359-6454.

Garofalo, F. (1963). Fundamentals of creep and creep-rupture in metals, MacMillan, New York, USA.

Harper, J.G. Shepard, L.A. \& Dorn, J.E. (1969). Creep of aluminum under extremely small stresses, Acta Metallurgica, Vol.6, No.7, (July 1958) pp.509-518, ISSN 0001-6160.

Imam, M.A. \& Gilmore, C.M. (1979). Room temperature creep of Ti-6Al-4V, Metallurgical Transactions A, Vol.10, No.4, (April 1979), pp.419-425, ISSN 1073-5623.

Kiefer T.F. \& Schwartzberg F.R. (1967). NASA-CR-92418.

Kiessel, W.R. \& Sinnott, M.J. (1953). Creep properties of commercially pure titanium, Journal of Metals, Vol.5, No.2, (February 1953), pp.331-338, ISSN 0148-6608.

Koike, J.; Ohyama, R.; Kobayashi, T.; Suzuki, M. \& Maruyama, K. (2003). Grain-Boundary Sliding in AZ31 Magnesium Alloys at Room Temperature to $523 \mathrm{~K}$, Materials Transactions, Vol.44, No.4, (April 2003), pp.445-451, ISSN 1345-9678.

Langdon, T.G. \& Mohamed, F.A. (1978). A simple method of constructing an Ashby-type deformation mechanism map, Journal of Materials Science, Vol.13, No.6, (June 1978), pp.1282-1290, ISSN 0022-2461. 
Luster, D.R.; Wentz W.W. \& Kaufman D.W. (1953). Creep properties of titanium, Materials and Methods, Vol.37, No.6, (June 1953), pp.100-103.

Matsunaga, T.; Kameyama, T.; Takahashi, K. \& Sato. E. (2009a). Constitutive Relation for Ambient-Temperature Creep in Hexagonal Close-Packed Metals, Materials Transactions, Vol.50, No.12, (December 2009) pp.2858-2864, ISSN 1345-9678.

Matsunaga, T.; Kameyama, T.; Takahashi, K. \& Sato. E. (2009b). Intragranular Deformation Mechanisms during Ambient-Temperature Creep in Hexagonal Close-Packed Metals, Materials Transactions, Vol.50, No.12, (December 2009) pp.2865-2872, ISSN 1345-9678.

Matsunaga, T.; Kameyama, T.; Ueda, S. \& Sato. E. (2010). Grain boundary sliding during ambient-temperature creep in hexagonal close-packed metals, Philosophical Magazine, Vol.90, No.30, (October 2010), pp.4041-4054, ISSN 1478-6435.

Mussot, P.; Rey, C. \& Zaoui, A. (1985). Grain boundary sliding and strain compatibility, Res Mechanica: International Journal of Structural Mechanics and Materials Science, Vol.14, No.1, (January-Mars 1985), pp.69-79, ISSN 0143-0084.

Neeraj, T.; Hou, D.H.; Daehn, G.S. \& Mills, M.J. (2000). Phenomenological and microstructural analysis of room temperature creep in titanium alloys, Acta Materialia, Vol.48, No.6, (April 2000), pp.1225-1238, ISSN 1359-6454.

Odegard B.C. \& Thompson A.W. (1974). Low temperature creep of Ti-6Al-4V, Metallurgical Transactions A, Vol.5, No.5, (May 1974), pp.1207-1213, ISSN 1073-5623.

Orowan, E. (1934). Zur Kristallplastizität. II - Die dynamische Auffassung der Kristallplastizität, Zeitschrift für Physik A Hadrons and Nuclei, Vol.89, No.9-10, (September 1934), pp.614-633, ISSN 0939-7922.

Parker, J.D. \& Wilshire, B. (1977). A surface measurement study of grain-boundary sliding during creep of a two-phase, copper-cobalt alloy, Materials Science and Engineering, Vol.29, No.3, (August 1977) pp.219-225.

Rae, C.M.F. \& Smith, D.A. (1980). On the mechanism of grain boundary migration, Philosophical Magazine A, Vol.41, No.4, (April 1980), pp.477-492, ISSN 0141-8610.

Reiman W.H. (1971). Room temperature creep in Ti-6Al-4V, Journal of Materials, Vol.6, No.4, (December 1971), pp.926-940.

Rust, M.A. \& Todd, R.I. (2011). Surface studies of region II superplasticity of AA5083 in shear: Confirmation of diffusion creep, grain neighbor switching and absence of dislocation activity, Acta Materialia, Vol.59, No.13, (August 2011) pp.5159-5170, ISBN 1359-6454.

Sato, E.; Yamada, T.; Tanaka, H. \& I. Jimbo (2006). Categorization of Ambient-Temperature Creep Behavior of Metals and Alloys on Their Crystallographic Structures, Materials Transactions, Vol.47, No.4, (April 2007), pp.1121-1126, ISSN 1345-9678.

Schober, T \& Balluffi, R.W. (1970). Quantitative observation on misfit dislocation arrays on low and high angle twist grain boundaries, Philosophical magazine, Vol.21, No.169, (January 1970), pp.109-124, ISSN 0031-8086.

Smith, D.A. \& King, A.H. (1981). On the mechanism of diffusion induced boundary migration, Philosophical Magazine A, Vol.44, No.2, (July 1981), pp.333-340, ISSN 0141-8610.

Spingarn, J.R.; Barnett, D.M. \& Nix, W.D. (1979). Theoretical descriptions of climb controlled steady state creep at high and intermediate temperatures, Acta Metallurgica, Vol.27, No.9, (September 1979), pp.1549-1561, ISSN 0001-6160. 
Suri, S.; Viswanathan, G.B.; Neeraj, T.; Hou, D.H. \& Mills, M.J. (1999). Room temperature deformation and mechanisms of slip transmission in oriented single-colony crystals of an $\alpha / \beta$ titanium alloy, Acta Materialia, Vol.47, No.3, (February 1999), pp.10191034, ISSN 1359-6454.

Takahashi, T. \& Horiuchi, R. (1985). Coupling of sliding and migration in coincidence boundaries of $\mathrm{Zn}$ and $\mathrm{Al}$ bicrystals and their DSC dislocation models, Transactions of Japan Institute of Metals, Vol.26, No.11, (November 1985), pp.786-794, ISSN 13459678.

Tanaka, H.; Yamada, T.; Sato, E. \& Jimbo, I. (2006). Distinguishing the Ambient-Temperature Creep Region in a Deformation Mechanism Map of Annealed CP-Ti, Scripta Materialia, Vol.54, No.1, (January 2006), pp.121-124, ISSN 1359-6462.

Thompson A.W. \& Odegard B.C. (1973). The influence of microstructure on low temperature creep of Ti-5Al-2.5Sn, Metallurgical Transactions A, Vol.4, No.4, (April 1973), pp.899-908, ISSN 1073-5623.

Valiev, R.Z. \& Kaibyshev, O.A. (1977). Mechanism of superplastic deformation in a magnesium alloy-2. The role of grain boundary, Physica Status Solidi (A), Vol.44, No.2, (December 1977), pp.477-484, ISSN 1862-6319.

Valiev, R.Z.; Korznikov, A.V. \& Mulyukov, R.R. (1993). Structure and properties of ultrafinegrained materials produced by severe plastic deformation, Material Science and Engineering A, Vol.168, No.2, (August 1993), pp.141-148, ISSN 0921-5093.

Watanabe, T.; Yamada, M.; Shima, S. \& Karashima, S. (1979). Misorientation dependence of grain boundary sliding in $<10 \overline{1} 0>$ tilt zinc bicrystals, Philosophical Magazine A, Vol.40, No.5, (November 1979), pp.667-683, ISSN 0141-8610.

Watanabe, T.; Kimura, S. \& Karashima, S. (1984). The effect of a grain boundary structural transformation on sliding in $<10 \overline{1} 0>$-tilt zinc bicrystals, Philosophical Magazine A, Vol.49, No.6, (Jun 1984) pp.845-864, ISSN 0141-8610. 


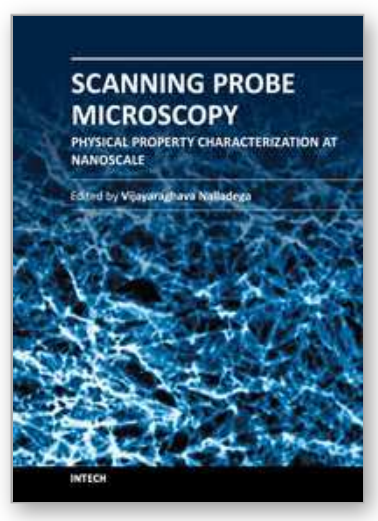

\section{Scanning Probe Microscopy-Physical Property Characterization at Nanoscale}

Edited by Dr. Vijay Nalladega

ISBN 978-953-51-0576-3

Hard cover, 242 pages

Publisher InTech

Published online 27, April, 2012

Published in print edition April, 2012

Scanning probe microscopy (SPM) is one of the key enabling tools for the advancement for nanotechnology with applications in many interdisciplinary research areas. This book presents selected original research works on the application of scanning probe microscopy techniques for the characterization of physical properties of different materials at the nanoscale. The topics in the book range from surface morphology analysis of thin film structures, oxide thin layers and superconducting structures, novel scanning probe microscopy techniques for characterization of mechanical and electrical properties, evaluation of mechanical and tribological properties of hybrid coatings and thin films. The variety of topics chosen for the book underlines the strong interdisciplinary nature of the research work in the field of scanning probe microscopy.

\section{How to reference}

In order to correctly reference this scholarly work, feel free to copy and paste the following:

Tetsuya Matsunaga and Eiichi Sato (2012). Estimation of Grain Boundary Sliding During Ambient-Temperature Creep in Hexagonal Close-Packed Metals Using Atomic Force Microscope, Scanning Probe Microscopy-

Physical Property Characterization at Nanoscale, Dr. Vijay Nalladega (Ed.), ISBN: 978-953-51-0576-3, InTech, Available from: http://www.intechopen.com/books/scanning-probe-microscopy-physical-propertycharacterization-at-nanoscale/estimation-of-grain-boundary-sliding-during-ambient-temperature-creep-in-hcpmetals-using-afm

\section{INTECH}

open science | open minds

\section{InTech Europe}

University Campus STeP Ri

Slavka Krautzeka 83/A

51000 Rijeka, Croatia

Phone: +385 (51) 770447

Fax: +385 (51) 686166

www.intechopen.com

\section{InTech China}

Unit 405, Office Block, Hotel Equatorial Shanghai

No.65, Yan An Road (West), Shanghai, 200040, China

中国上海市延安西路65号上海国际贵都大饭店办公楼 405 单元

Phone: +86-21-62489820

Fax: $+86-21-62489821$ 
(C) 2012 The Author(s). Licensee IntechOpen. This is an open access article distributed under the terms of the Creative Commons Attribution 3.0 License, which permits unrestricted use, distribution, and reproduction in any medium, provided the original work is properly cited. 